\title{
Performance of a zero-inertia model for irrigation with rapidly varied inflow discharges
}

\author{
Kaihua Liü ${ }^{1,2}$, Xiyun Jiao ${ }^{1,2,3^{*}}$, J iang $\mathrm{Li}^{2}$, Yunhao $\mathrm{An}^{1,2}$, Weihua Guo², \\ Mohamed Khaled Salahou ${ }^{1}$, Honghui Sang ${ }^{1,2}$ \\ (1. State Key Laboratory of Hydrology-Water Resources and Hydraulic Engineering, Hohai University, Nanjing 210098, China; \\ 2. College of Agricultural Engineering, Hohai University, Nanjing 210098, China; \\ 3. Cooperative Innovation Center for Water Safety and Hydro Science, Hohai University, Nanjing 210098, China)
}

\begin{abstract}
The zero-inertia model is widely used for simulating surface flow in irrigation systems. This model is accurate when inflow discharge is constant. However, simulation of irrigation systems with rapidly varied inflow discharge is needed due to the development of real time control irrigation technology. Hence, the objective of this study is to validate the zero-inertia model with rapidly varied inflow discharge. For this purpose, twenty-three border irrigation tests at a range of inflow changes on different field slopes and roughness coefficients were conducted. Then, the sensitivity analyses of bed slope, infiltration parameters, and roughness coefficient were examined. The results indicate that the zero-inertia model predictions are in good agreement with field data in both advance/recession times and flow depths. The infiltration parameters were the most sensitive input variable of the zero-inertia model. The input variables have a more considerable impact on the recession phase than the advance phase.
\end{abstract}

Keywords: zero-inertia model, rapidly varied inflow, border irrigation, sensitivity analysis DOI: $10.25165 /$ j.ijabe.20201302.5228

Citation: Liu K H, Jiao X Y, Li J, An Y H, Guo W H, Salahou M K, et al. Performance of a zero-inertia model for irrigation with rapidly varied inflow discharges. Int J Agric \& Biol Eng, 2020; 13(2): 175-181.

\section{Introduction}

Surface irrigation is still the most common method for irrigating crops across the world. Numerical simulation of surface irrigation flow can provide the necessary tools to simulate, design and evaluate irrigation systems. Since the 1970s, with the popularization of computer application, the numerical simulation model of surface irrigation has developed rapidly. At present, there are mainly four mathematical models.

The full hydrodynamic model is recognized as the accurate description of the water flow in surface irrigation ${ }^{[1]}$. It is based on Saint-Venant long wave equations, which are two separate hyperbolic partial differential equations and include a mass conservation equation and a momentum equation. Because these equations are hard to solve algebraically in the purest form, numerical solution methods, such as the finite difference method $^{[2,3]}$, the method of characteristics ${ }^{[4]}$, the finite element

Received date: 2019-07-11 Accepted date: 2020-02-23

Biographies: Kaihua Liu, $\mathrm{PhD}$, research interests: theory and technology of water-saving irrigation, Email: 150402060005@hhu.edu.cn; Jiang Li, Lecturer, research interests: agricultural hydrology, Email: lijiang@hhu.edu.cn; Yunhao An, $\mathrm{PhD}$, research interests: theory and technology of water-saving irrigation, Email: 170402060004@hhu.edu.cn; Weihua Guo, Lecturer, research interests: agricultural water and soil resources management, Email: 20140058@hhu.edu.cn; Mohamed Khaled Salahou, Post-doctoral, research interests: agricultural water and soil resources management, Email: salahou3@hotmail.com or salahou@hhu.edu.cn; Honghui Sang, PhD, research interests: agricultural water and soil resources management, Email: 15651830673@163.com

*Corresponding author: Xiyun Jiao, Professor, research interests: theory and technology of water-saving irrigation, State Key Laboratory of Hydrology-Water Resources and Hydraulic Engineering, College of Agricultural Engineering, Hohai University, Nanjing 210098, China. Tel: +86-13901594610; Email: xyjiao@hhu.edu.cn. $\operatorname{method}^{[5]}$ and the finite volume method ${ }^{[6]}$, were used to obtain the numerical solution. Although the full hydrodynamic model can provide an accurate simulation, sometimes it is numerically sensitive, and existing a numerical oscillation ${ }^{[7]}$. Additionally, the complexity also limits its wide application. For these reasons, Strelkof and Katopodes ${ }^{[8]}$ introduced the zero-inertia model based on the full hydrodynamic model. Removing the inertial, or acceleration, terms in the momentum equation simplifies the calculation and increases the operation speed as well as robustness $^{[1,9]}$, and the result is still accurate ${ }^{[10]}$. The kinematic-wave model further simplifies Saint-Venant long wave equations by assuming that the water surface slope deviates little from the bed slope. Some experiments verified the model can be used to simulate the advance and recession curves ${ }^{[11]}$. However, the kinematic-wave model accuracy is limited by the field slope and soil textures ${ }^{[10]}$. The volume balance model is the simplest model. The momentum equation is neglected, and the amount of irrigation water usually approximated by flow and infiltration depth at the key points of field, the shape factor and the advance distance $^{[12]}$. However, the volume balance model is rarely used, because it is hard to guarantee its accuracy.

The zero-inertia model has been widely used for simulation in surface irrigation systems and proved to be accurate when inflow discharge is constant ${ }^{[13]}$. However, with the development of automatic irrigation technology, such as the self-adaptive control of surface irrigation $^{[14]}$, inflow discharge is not always constant, and the inflow discharge may also be suddenly adjusted. Saint-Venant long wave Equations is not strictly fit to rapidly varied unsteady flow ${ }^{[15]}$. Szydtowski and Zima ${ }^{[16]}$ investigated rapidly varied open channel flow due to dam-break effect and pointed out that Saint-Venant long wave Equations can simulate dam-break water flow although they cannot well describe the flow near the local 
hydraulic effects. However, the surface irrigation system is more complex and microscopic than open channel transportation system, which means that the errors caused by rapidly varied inflow are likely to amplify. In this case, the applicability of zero-inertia model, which is derived from the simplification of Saint-Venant Equations need to be verified by field measurements. At present, there are few studies on the surface irrigation system with rapidly varied inflow, and related field experiments are also lacking. Hence, the objectives of this study were as follows: (1) to validate the applicability of the zero-inertia model (23 border irrigation experiments were conducted for this purpose); and (2) to analyze the sensitivity of system inputs to provide recommendations for future experimental measurement in rapidly varied inflow irrigation system.

\section{Materials and methods}

\subsection{Field measurements}

\subsubsection{Study area}

Experiments were carried out in a wheat field at the CAS Ecological Agricultural Experiment Station in the town of Nanpi in Hebei Province, China $\left(116^{\circ} 40^{\prime} \mathrm{E}, 38^{\circ} 06^{\prime} \mathrm{N}\right)$. The region is in a warm temperate zone and has a semi-humid monsoon climate. The annual rainfall ranges from $500 \mathrm{~mm}$ to $600 \mathrm{~mm}$, and generally occurs during the summer (about $73 \%$ of the whole year). The annual evaporation is between $1500 \mathrm{~mm}$ and $1800 \mathrm{~mm}$. The groundwater depth is below $2 \mathrm{~m}$. The surface soil is a silt loam, and the dry bulk density is $1.48 \mathrm{~g} / \mathrm{cm}^{3}$ at depth of $1 \mathrm{~m}$. The farming in study area is carried out according to the local perennial crop. Winter wheat is the main crop and planted in October, and generally harvested in next June.

\subsubsection{Experiment design and measurement}

A total of 23 border irrigation tests were conducted. The tested borders were divided into two groups (Group A: A1 to A12 and Group B: B1 to B11). Group A was carried out in 2016, and each border in this group was designed to be $80 \mathrm{~m}$ in length and $3.7 \mathrm{~m}$ in width. Group B was carried out in 2018 , and each border in this group was designed to be $100 \mathrm{~m}$ in length and $3 \mathrm{~m}$ in width. Similar to the border used by local farmers, all test borders were closed-ended. In order to be comprehensive, the inflow discharge for borders A1 to A3 and for borders B1 to B4 was constant. And the inflow discharge for borders A4 to A12 and for borders B5 to B11 was rapidly varied.

To better cover the wide range of irrigation practices, the inflow rate ranged between $2-7 \mathrm{~L} / \mathrm{s} \cdot \mathrm{m}^{[17,18]}$. Hence, the inflow rates within or slightly larger than this range were arranged at the study area. The irrigation pipe system of Group A is designed with a valve to regulate inflow rate. However, it is very difficult to control the inflow rate with the valves. This resulted in inconsistent inflow rate for almost every border. In order to make the experiment better controlled, an improvement was implemented in Group B. Three independent irrigation pipe systems were used, and the inflow rate is fixed in each of them at $2.4 \mathrm{~L} / \mathrm{s} \cdot \mathrm{m}$, $4.17 \mathrm{~L} / \mathrm{s} \cdot \mathrm{m}$ and $6.5 \mathrm{~L} / \mathrm{s} \cdot \mathrm{m}$. During the irrigation events, the irrigation pipe systems were all opened to ensure that the inflow rates were stable. When the inflow discharge needs to be changed, the corresponding irrigation pipe was linked in.

According to local farming practices, the machine levels the land while sowing. There is no professional machine to level the land, so the field is not well leveled. For each border, longitudinal slopes were measured with $5 \mathrm{~m}$ interval. All border slopes were generally downward, except a few intervals in some borders are inclined upward.

Soil was classified as a silt loam based on particle size (65.53\% silt, $21.75 \%$ sand, and $12.72 \%$ clay on average). Irrigation inflow rates were measured by electromagnetic flow meters (accuracy of $\pm 1.5 \%$ ). The infiltration parameters $k$ and $\alpha$ of the Kostiakov Equation were derived by the soil moisture before and after irrigation at two observation points, and the equations can be written as Equations (1) and (2). The roughness coefficient of border was determined by the zero-inertia model and the trial and error approach $^{[17,19]}$, since it is difficult to measure or calculate it directly. The different values of roughness coefficient were fed into the zero-inertia model. Then, the simulated advance and recession trajectories of the model were compared with the observed data, and when a good fit between them was achieved, the actual roughness coefficient was established.

$$
\begin{gathered}
\alpha=\frac{\ln \left(z_{1} / z_{2}\right)}{\ln \left(t_{1} / t_{2}\right)} \\
k=\frac{z_{1}}{t_{1}^{\alpha}}
\end{gathered}
$$

where, $z_{1}$ and $z_{2}$ are the cumulative infiltration of observation points 1 and 2 respectively, $\mathrm{m} ; t_{1}$ and $t_{2}$ are the infiltration times of observation points 1 and 2 respectively, s.

\subsection{Computational schemes}

The zero-inertia model are composed of a mass conservation equation and a simplified momentum equation, and these equations can be written as:

$$
\begin{gathered}
\frac{\partial q}{\partial x}+\frac{\partial h}{\partial t}+\frac{\partial z}{\partial t}=0 \\
\frac{\partial h}{\partial x}=s_{0}-s_{\mathrm{f}}
\end{gathered}
$$

where, $x$ is the distance from the upper end of the channel, $\mathrm{m}$; $t$ is the time from the beginning of inflow, $\mathrm{s} ; q$ is the discharge per unit width, $\mathrm{m}^{3} /(\mathrm{s} \cdot \mathrm{m}) ; h$ is flow depth, $\mathrm{m} ; z$ is the cumulative infiltration, $\mathrm{m} ; s_{0}$ is the border slope; $s_{\mathrm{f}}$ is the friction slope, and it can be written as:

$$
s_{\mathrm{f}}=\frac{Q^{2} n^{2}}{A^{2} R^{\frac{4}{3}}} \approx \frac{V^{2} n^{2}}{h^{\frac{4}{3}}}
$$

where, $Q$ is volume flow rate, $\mathrm{m}^{3} / \mathrm{s} ; A$ is the cross-sectional area of flow, $\mathrm{m}^{2} ; n$ is roughness coefficient.

Kostiakov Equation is the most frequently used infiltration equation in the numerical simulation of surface irrigation:

$$
Z=k t^{\alpha}
$$

where, $k\left(\mathrm{~m} / \mathrm{s}^{\alpha}\right)$ and $\alpha$ are empirical coefficients.

The numerical solution follows the finite difference method, similar to that presented by Mcclymont ${ }^{[1]}$. The time-space computation grid is a rectangular grid system as depicted in Figure 1. The time step is invariant, and the space step is variable. The subscript referencing J, M, L and R represent the variable's grid cell representation and the basic equations (Equations (3) and (4)) can be transformed into finite difference form and written as:

$$
\begin{gathered}
{\left[\theta q_{\mathrm{R}}+(1-\theta) q_{\mathrm{M}}-\theta q_{\mathrm{L}}-(1-\theta) q_{\mathrm{J}}\right] \mathrm{d} t} \\
+\left[\varphi h_{\mathrm{R}}+(1-\varphi) h_{\mathrm{L}}-\varphi h_{\mathrm{M}}-(1-\varphi) h_{\mathrm{J}}\right] \mathrm{d} x \\
+\left[\varphi z_{\mathrm{R}}+(1-\varphi) z_{\mathrm{L}}-\varphi z_{\mathrm{M}}-(1-\varphi) z_{\mathrm{J}}\right] \mathrm{d} x=R_{C} \\
{\left[\theta q_{\mathrm{R}}+(1-\theta) q_{\mathrm{M}}-\theta q_{\mathrm{L}}-(1-\theta) q_{\mathrm{J}}\right]+\left[-s_{0}+\theta \varphi s_{f \mathrm{R}}+\right.} \\
\left.(1-\theta) \varphi s_{f \mathrm{M}}+\theta(1-\varphi) s_{f \mathrm{~L}}+(1-\theta)(1-\varphi) s_{f \mathrm{~J}}\right] \mathrm{d} x=R_{M}
\end{gathered}
$$


where, $\theta$ and $\varphi$ are the space-averaging and time-averaging coefficients, and these values are typically equal to $0.6^{[1]} ; R_{\mathrm{C}}$ and $R_{\mathrm{M}}$ are residuals from the continuity and momentum equations respectively, and these values should theoretically be equal to zero.

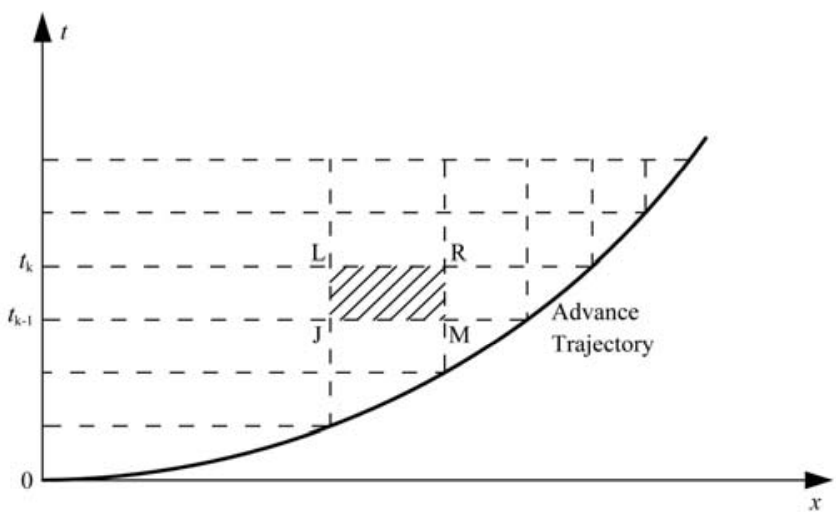

Figure 1 Time-space computation grid

The solution is implicit, so the basic equations should be solved simultaneously for all cells at each time step. The following is illustrated by an example of the calculation of period of $t_{\mathrm{k}-1}$ (known) to $t_{\mathrm{k}}$ (unknown). Assuming that the number of cells at $t_{\mathrm{k}}$ is $\mathrm{N}$ (the number of unknown points at $t_{\mathrm{k}}$ is $\mathrm{N}+1$ ). Each call can establish two equations, together with the boundary conditions, so the total number of equations is $2 \mathrm{~N}+2$. There are two variables at each unknown point ( $q$ and $h$ ), so the total number of variables is also $2 \mathrm{~N}+2$. The double-sweep method described by Walker and Skogerboe ${ }^{[20]}$ and Mcclymont ${ }^{[1]}$ was used to solve these implicit equations.

\subsection{Statistical analysis}

The accuracy of the modified model could be evaluated by the coefficient of determination $\left(R^{2}\right)$, root mean square error (RMSE) and coefficient of residual mass $(\mathrm{CRM})^{[21]} . \quad R^{2}$ varies from zero to one, and the larger it is, the more valuable simulation results are. The RMSE has minimum value of zero, and the closer it gets to zero, the more accurate the simulation results are. CRM can be negative or positive, and it indicates the underestimation or overestimation amounts of predictions. $R^{2}$, RMSE and CRM can be written as:

$$
\begin{gathered}
R^{2}=1-\frac{\sum_{i=1}^{n}\left(t_{p}-t_{m}\right)_{i}{ }^{2}}{\sum_{i=1}^{n}\left(t_{m}-\bar{t}\right)_{i}{ }^{2}} \\
\mathrm{RMSE}=\sqrt{\frac{\sum_{i=1}^{n}\left(t_{p}-t_{m}\right)_{i}{ }^{2}}{n}} \\
\mathrm{CRM}=\frac{\sum_{i=1}^{n}\left(t_{p}-t_{m}\right)_{i}}{\sum_{i=1}^{n} t_{m}}
\end{gathered}
$$

where, $t_{p}$ is the calculated advance/recession time, $\min ; t_{m}$ is the measured advance/recession time, min; $\bar{t}$ is the mean of the measured advance/recession time, min; $n$ is the number of stations along the border length.

\section{Results and discussion}

\subsection{Experimental data}

Table 1 provides the longitudinal slopes of every border each $5 \mathrm{~m}$. Although the average slope of each border was about 0.002 , the field was not very flat. This indicates that local traditional farming methods did not perform very well in field levelling. Table 2 provides details of the inflow rate, inflow change time, cut-off time, Kostiakov infiltration parameters and roughness coefficient. These were used as input parameters of the zero-inertia model for each irrigation event to simulate the advance

\begin{tabular}{|c|c|c|c|c|c|c|c|c|c|c|c|c|c|c|c|c|c|c|c|c|c|}
\hline \multirow{2}{*}{$\begin{array}{l}\text { Border } \\
\text { number }\end{array}$} & \multicolumn{20}{|c|}{ Average slope of each $5 \mathrm{~m}$} & \multirow{2}{*}{$\begin{array}{c}\text { Average } \\
\text { slope }\end{array}$} \\
\hline & $0-5$ & & $10-15$ & $15-20$ & $0-25$ & $25-30$ & $30-35$ & $35-40$ & $40-45$ & $45-50$ & $50-55$ & $55-60$ & $60-65$ & & $0-75$ & $75-80$ & $80-85$ & & $90-95$ & $95-100$ & \\
\hline Al & & & & & & & & & & & & & & & & & & & & & \\
\hline A2 & 0.0044 & .0032 & .0010 & .0000 & .0004 & 0006 & 0.0014 & 0.0018 & & & & & 0.0046 & -0.0044 & & & - & - & - & - & 0.0021 \\
\hline $\mathrm{A} 3$ & -0.0106 & 0.0028 & 0.0052 & -0.0018 & 0.0020 & -0.0004 & 0.0042 & 0.0022 & 0.0014 & 0.0024 & 0.0072 & -0.0020 & 0.0014 & 0.0046 & 0.0088 & 0.0005 & - & . & 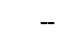 & - & 0.0017 \\
\hline A4 & -0.0020 & -0.0024 & 0.0102 & -0.0038 & 0.0042 & .0046 & -0.0040 & 0.0036 & 0.0050 & 0.0034 & -0.0002 & 0.0052 & -0.0038 & 0.0044 & 0.0096 & -0.0066 & - & - & - & - & 0.0017 \\
\hline A6 & 0.0024 & 0.0006 & 0.0064 & 0.0034 & 0.0008 & 0032 & 0.0018 & 0.0008 & 0.0014 & 0.0046 & 0.0040 & 0.0002 & 0.0012 & & 0.0038 & 0.0046 & - & . & 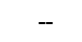 & - & 0.0025 \\
\hline A7 & 0.0000 & .0018 & 0.0016 & 0.0012 & 0.0040 & .0030 & 0.0012 & 0.0000 & 0.0058 & & 40.0034 & 0.0048 & & 0.0060 & 0.0058 & 0.0020 & - & - & - & - & 0.0024 \\
\hline A8 & 0.0004 & 0.0114 & -0.0024 & 40.0022 & 0.0020 & .0010 & 0.0006 & 0.0034 & 0.0050 & 0.0058 & -0.0034 & 0.0032 & 0.0046 & 0.0004 & 0.0038 & & - & - & - & - & 0.0025 \\
\hline A9 & -0.0006 & 0.0012 & 0.0030 & -0.0008 & 0.0020 & .0044 & & 0.0030 & 0.0038 & 0.0022 & -0.0040 & 0.0038 & -0.0005 & 0.0030 & 0.0024 & 0.0010 & & & & - & 0.0014 \\
\hline A10 & -0.0016 & 0.0024 & 0.0030 & & 0.0017 & .0020 & & 0.0024 & 0.0026 & & 20.0038 & & & & 0.0058 & & - & - & - & - & 0.0012 \\
\hline A11 & -0.0014 & 0.0008 & 0.0052 & & 0.0012 & 0.0088 & 0.0062 & & 0.0014 & 0.0004 & 0.0082 & 0.0032 & 0.0008 & 0.0056 & 0.0022 & 0.0040 & - & - & - & - & 0.0027 \\
\hline B1 & 0.0040 & 0.0015 & 0.0010 & 0.0017 & 0.0018 & 0010 & 0.0017 & & 0.0021 & 0.0010 & 0.0010 & & & & & & 0.0020 & 0.00 & & & 0.0016 \\
\hline B2 & 0.0016 & 0.0013 & 0.0013 & 0.0039 & & 0.0001 & & & 0.0019 & & & 0.0005 & & 0.0005 & 0.0007 & 0.0007 & & 0.0046 & 0.0038 & & 0.0018 \\
\hline B3 & 0.0024 & 0.0027 & 0.0015 & 0.0021 & 0.0034 & 0.0010 & 0.0021 & 0.0011 & 0.0030 & 0.0007 & 0.0005 & 0.0005 & 0.0008 & 0.0005 & 0.0002 & 0.0006 & 0.0005 & 0.0041 & 0.0045 & 0.0043 & 0.0018 \\
\hline B4 & 0.0025 & 0.0013 & 0.0010 & 0.0031 & 0.0010 & 0.0017 & 0.0011 & 0.0008 & 0.0026 & 0.0005 & 0.0013 & 0.0015 & 0.0011 & 0.0018 & 0.0015 & 0.0015 & 0.0044 & 0.0047 & 0.0 & 0.0030 & 0.0020 \\
\hline B5 & 0.0018 & 0.0010 & 0.0019 & 0.0020 & 0.0025 & 0.0009 & 0.0021 & 0.0011 & & 0.0002 & & & 0.0001 & & 0.0000 & 0.0003 & 0.0013 & 0.0030 & 0.0045 & & 0.0015 \\
\hline B6 & 0.0023 & 0.0004 & 0.0017 & 0.0031 & 0.0020 & 0.0021 & 0.0006 & 0.0010 & 0.0029 & 0.0013 & 0.0006 & 0.0003 & 0.0000 & 0.0004 & 0.0003 & 0.0013 & 0.0017 & 0.0029 & & & 0.0016 \\
\hline B7 & 0.0009 & 0.0019 & 0.0009 & 0.0029 & 0.0018 & 0.0011 & 0.0007 & 0.0023 & 0.0025 & 0.0010 & 0.0002 & 0.0011 & 0.0003 & 0.0003 & 0.0017 & 0.0022 & 0.0033 & 0.0026 & 0.0017 & 0.0032 & 0.0016 \\
\hline B8 & 0.0013 & 0.0009 & 0.0028 & 0.0010 & 0.0026 & 0.0001 & 0.0008 & 0.0026 & 0.0039 & 0.0011 & 0.0011 & 0.0015 & 0.0005 & 0.0007 & 0.0010 & 0.0020 & 0.0023 & 0.0039 & 0.0015 & 0.0023 & 0.0017 \\
\hline B9 & 0.0009 & 0.0011 & 0.0001 & 0.0027 & 0.0031 & 0.0004 & 0.0018 & 0.0016 & 0.0005 & 0.0019 & 0.0023 & 0.0003 & 0.0019 & 0.0001 & 0.0013 & 0.0029 & 0.0049 & 0.0051 & 0.0017 & & 0.0019 \\
\hline B10 & 0.0017 & 0.0013 & 0.0038 & 0.0005 & 0.0013 & 0.0001 & 0.0016 & 0.0014 & 0.0030 & 0.0009 & 0.0010 & 0.0006 & 0.0033 & 0.0010 & 0.0030 & 0.0050 & 0.0020 & 0.0057 & 0.0031 & 0.0023 & 0.0021 \\
\hline B11 & 0.0024 & 0.0044 & 0.0020 & 0.0005 & -0.0010 & 0.0010 & 0.0020 & 0.0009 & 0.0015 & 0.0019 & 0.0009 & 0.0002 & -0.0017 & 0.0030 & -0.0020 & 0.0007 & 0.0055 & 0.0020 & 0.0029 & 0.0032 & 0.0015 \\
\hline
\end{tabular}
trajectories, recession trajectories and flow depths.

\section{Table 1 Observational slope of each border}


Table 2 Observational data of border irrigation tests, Kostiakov parameters and Roughness coefficient

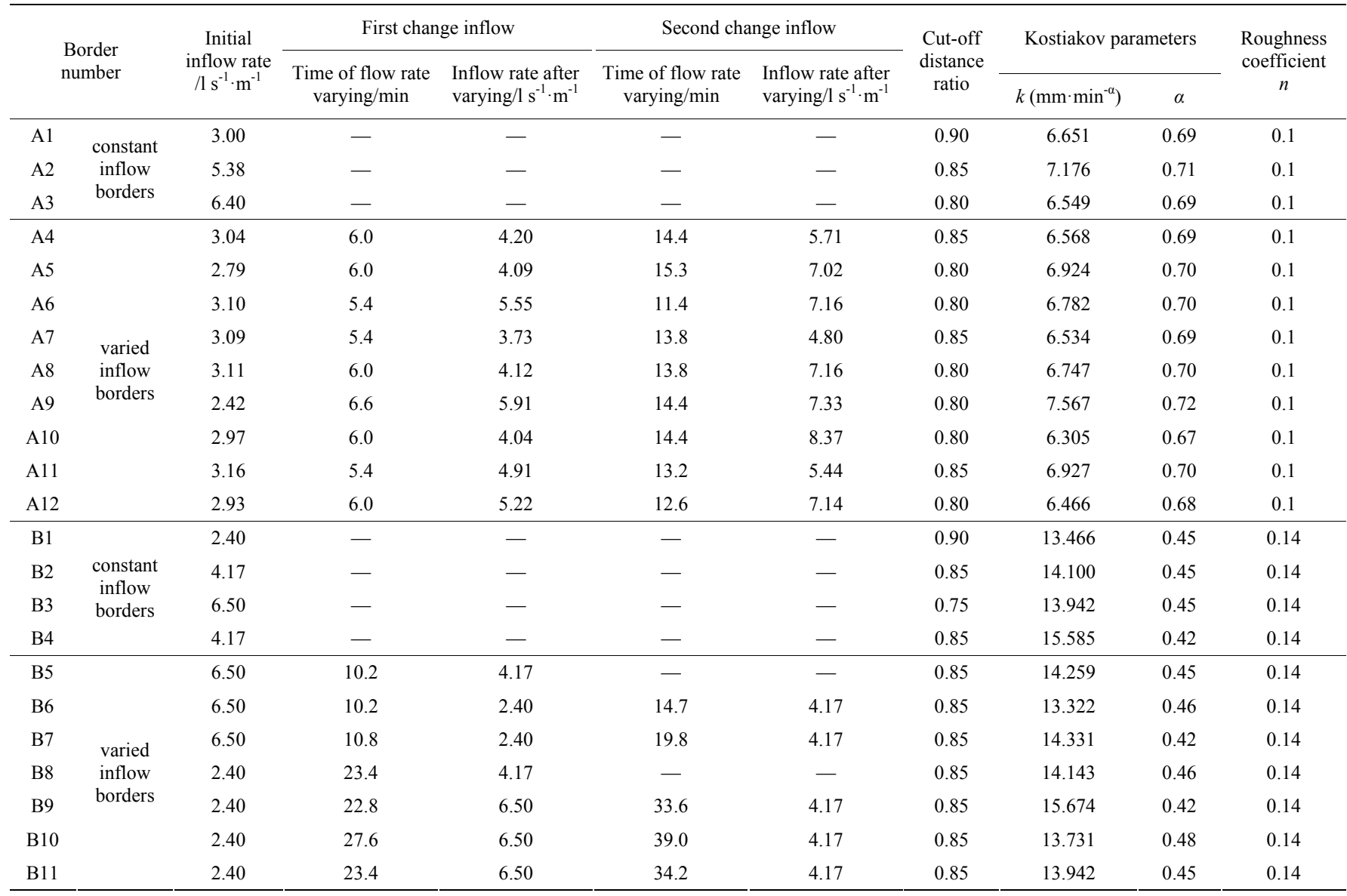

\subsection{Validation}

The applicability of the zero-inertia model in the border irrigation system with rapidly varied inflow was validated by comparing the predicted advance time, recession time and flow depth with observed field study data.

The predicted advance and recession trajectories by the zero-inertia model were compared with the field measured data and the result are presented in Figures 2 and 3. The results showed that the simulations were in good agreement with field data.

For details, in borders with constant inflow discharge (borders A1 to $\mathrm{A} 3$ and borders $\mathrm{B} 1$ to $\mathrm{B} 4)$, the relative error was mostly within $10 \%$ for simulated advance times and $15 \%$ for recession times, and the average relative error was $6.36 \%$ and $9.46 \%$ for advance and regression times, respectively. In borders with varied inflow discharge, the relative error was mostly within $15 \%$ for simulated advance times and $20 \%$ for recession times, and the

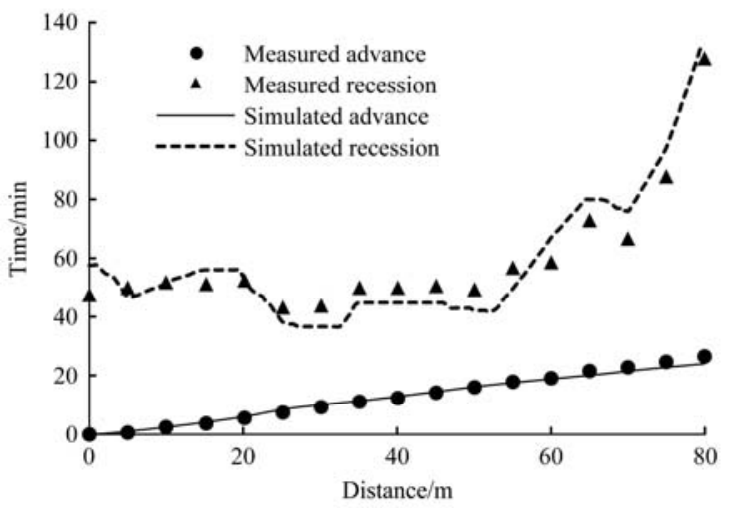

a. Border A12 average relative error was $7.24 \%$ and $10.32 \%$ for advance and regression times, respectively. The relative errors were similar to other results of the border irrigation simulation. For examples, Zhang et al. ${ }^{[22]}$ simulated the border irrigation system by Roe finite-volume method and improved hybrid numerical method, the average relative error of simulated advance and recession times was $4.9 \%$ and $7.38 \%$ for the improved hybrid numerical method, $6.88 \%$ and $9.45 \%$ for the Roe finite-volume method. Mahdizadeh Khasraghi et al. ${ }^{[13]}$ simulated the cultivated closed-end border irrigation system by the zero-inertia model and full hydrodynamic model in the SIRMOD software. Except for the abnormal experimental data (ROTH-16 test), the average relative error of simulated advance and recession times was $7.49 \%$ and $14.09 \%$ for the zero-inertia model, $7.49 \%$ and $15.36 \%$ for the full hydrodynamic model. Therefore, the simulation results in this study are acceptable.

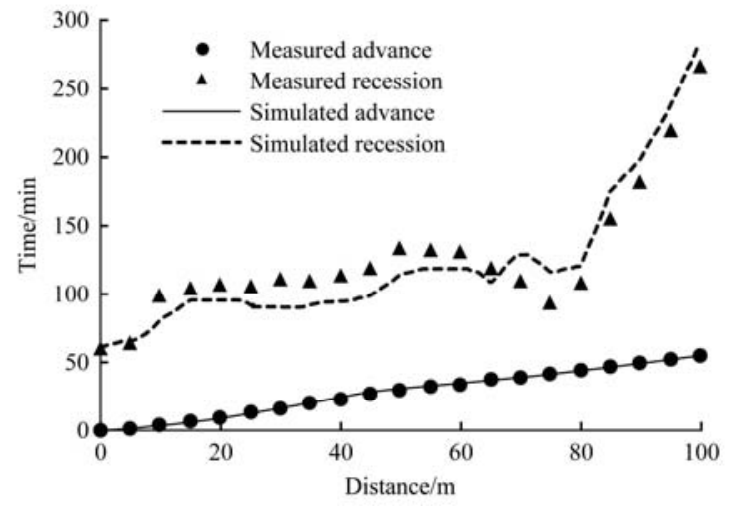

b. Border B11

Figure 2 Comparison of simulated and measured advance and recession trajectories for border A12, border B11 


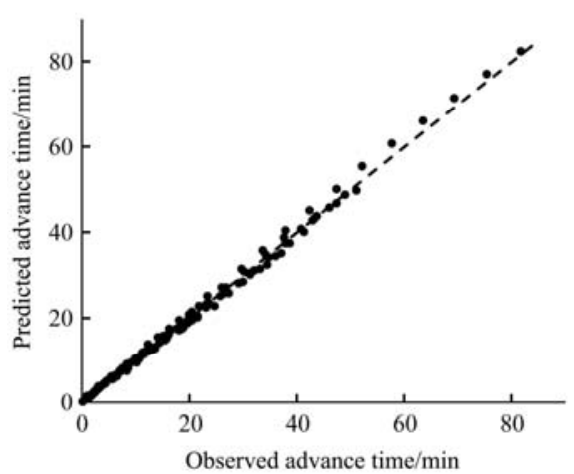

a. Advance time in constant inflow borders

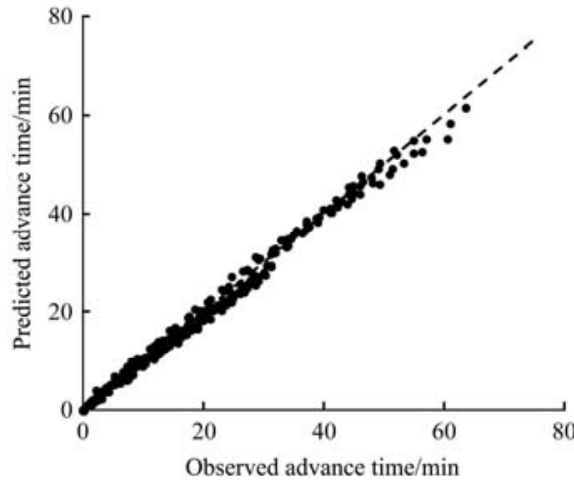

c. Advance time in varied inflow borders

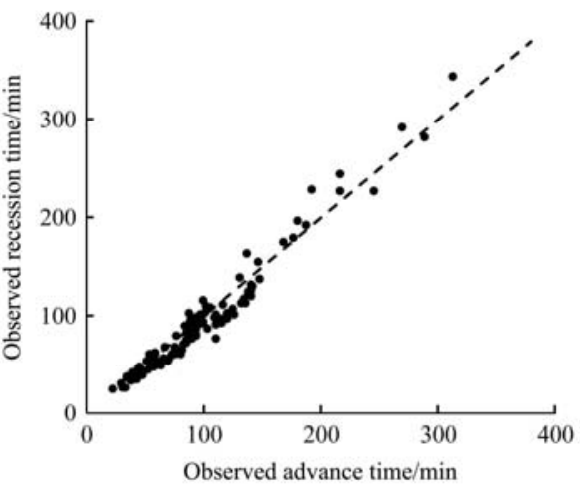

b. Recession time in constant inflow borders

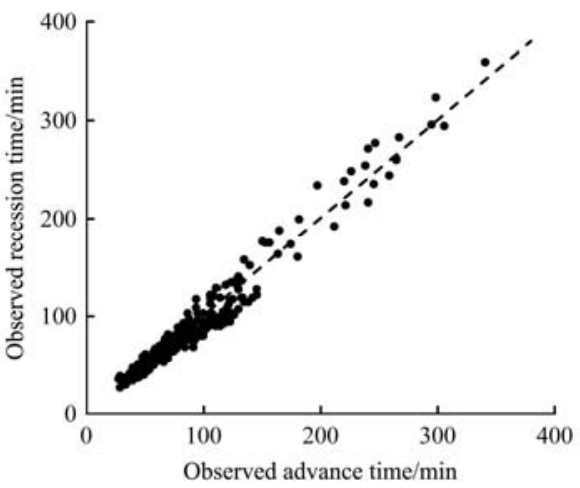

d. Recession time in varied inflow borders

Figure 3 Observed versus predicted advance and recession times for the total data of borders with Zero-inertia model

Several statistics indicators were computed to further verify the accuracy of the zero-inertia model. The results showed that the zero-inertia model have a fair degree of accuracy (Table 3). In the irrigation events with constant inflow discharge, the values of $R^{2}$ were between 0.993 and 0.999 for simulated advance times, and between 0.874 and 0.940 for simulated recession times. And in the irrigation events with rapidly varied inflow, the values of $R^{2}$ were between 0.960 and 0.998 for simulated advance times, and between 0.852 and 0.961 for simulated recession times. Although the values of $R^{2}$ for the irrigation events with rapidly varied inflow was slightly smaller, it still showed a high correlation of the zero-inertia model with the measured data ${ }^{[23]}$. The values of RMSE and CRM have the same tendency. In the irrigation events with constant inflow, the values of RMSE were between 0.496 and $1.793 \mathrm{~min}$ for simulated advance times, and between 1.852 and $15.757 \mathrm{~min}$ for simulated recession times respectively. The values of CRM were between -0.032 and 0.043 for simulated advance times, between -0.104 and 0.029 for simulated recession times respectively. And in the irrigation events with rapidly varied inflow, the values of CRM were between -0.103 and 0.047 for simulated advance times, between -0.103 and 0.014 for simulated recession times respectively. In the irrigation events with rapidly varied inflow, the values of RMSE were between $0.729 \mathrm{~min}$ and $2.317 \mathrm{~min}$ for simulated advance times, between $4.343 \mathrm{~min}$ and $17.280 \mathrm{~min}$ for simulated recession times respectively. These results agreed with other researches of the constant-discharge surface irrigation simulation. Mahdizadeh Khasraghi et al. ${ }^{[13]}$ used SIRMOD software to simulate 22 sets of border irrigation with constant inflow discharge, and the average value of RMSE was $1.11 \mathrm{~min}$ for simulated advance times and $10.93 \mathrm{~min}$ for simulated recession times. Sayari et al. ${ }^{[24]}$ used the SIRMOD software and a zero-inertia finite element model to simulate the flow in surface irrigation with constant inflow discharge, and the RMSE values of simulated recession times were between $2.80 \mathrm{~min}$ and $12.58 \mathrm{~min}$ for the zero-inertia finite element model, between $2.26 \mathrm{~min}$ and $17.89 \mathrm{~min}$ for SIRMOD. Hence, the zero-inertia model is satisfactory to simulate the advance and recession phase in border irrigation with rapidly varied inflow discharges.

Table 3 Goodness of fit of Zero-inertia model

\begin{tabular}{|c|c|c|c|c|c|c|c|}
\hline & & & lvance ti & & & cession $t$ & \\
\hline & Imber & $R^{2}$ & RMSE & CRM & $R^{2}$ & RMSE & CRM \\
\hline A1 & constant & 0.999 & 0.496 & -0.004 & 0.904 & 1.852 & 0.017 \\
\hline A2 & inflow & 0.993 & 0.616 & 0.035 & 0.908 & 2.298 & 0.009 \\
\hline A3 & borders & 0.994 & 0.515 & -0.006 & 0.893 & 5.438 & -0.046 \\
\hline A4 & & 0.960 & 1.963 & -0.103 & 0.866 & 7.681 & 0.014 \\
\hline A5 & & 0.983 & 1.275 & -0.062 & 0.873 & 6.933 & -0.044 \\
\hline A6 & & 0.990 & 0.781 & -0.035 & 0.892 & 6.282 & -0.041 \\
\hline A7 & varied & 0.992 & 0.862 & -0.040 & 0.878 & 4.343 & -0.062 \\
\hline A 8 & inflow & 0.992 & 0.830 & -0.052 & 0.865 & 4.792 & -0.088 \\
\hline A9 & borders & 0.984 & 1.180 & -0.036 & 0.852 & 5.303 & -0.003 \\
\hline A10 & & 0.980 & 1.351 & -0.020 & 0.909 & 6.203 & 0.007 \\
\hline A11 & & 0.967 & 1.634 & -0.091 & 0.894 & 5.510 & -0.038 \\
\hline A12 & & 0.988 & 0.898 & -0.030 & 0.900 & 6.471 & 0.004 \\
\hline B1 & & 0.995 & 1.793 & 0.043 & 0.874 & 11.506 & -0.022 \\
\hline B2 & constant & 0.998 & 0.630 & -0.018 & 0.930 & 14.391 & -0.104 \\
\hline B3 & borders & 0.993 & 0.937 & 0.010 & 0.878 & 14.849 & -0.095 \\
\hline B4 & & 0.996 & 1.000 & -0.032 & 0.940 & 15.757 & 0.029 \\
\hline B5 & & 0.997 & 0.729 & 0.031 & 0.917 & 11.698 & -0.014 \\
\hline B6 & & 0.995 & 1.066 & 0.036 & 0.918 & 13.718 & -0.103 \\
\hline B7 & varied & 0.996 & 0.904 & -0.030 & 0.961 & 15.138 & -0.080 \\
\hline B8 & inflow & 0.995 & 1.407 & -0.018 & 0.889 & 17.280 & -0.090 \\
\hline B9 & borders & 0.993 & 1.307 & 0.047 & 0.932 & 15.318 & -0.022 \\
\hline B10 & & 0.985 & 2.317 & -0.061 & 0.897 & 17.248 & -0.016 \\
\hline B11 & & 0.998 & 0.740 & -0.001 & 0.877 & 16.261 & -0.029 \\
\hline
\end{tabular}


As water enters the border from the upper boundary, the flow depth fluctuates near the upper boundary. The flow depth observation points are designed at a quarter distance $(20 \mathrm{~m}$ in Field A and $25 \mathrm{~m}$ in Field B) from the upper boundary of the border. Flow depths were measured by capacitance water level logger (resolution: $1 \mathrm{~mm}$ ). The observation time interval of Field A (in 2016) was too long (about $2 \mathrm{~min}$ ) to understand how the water

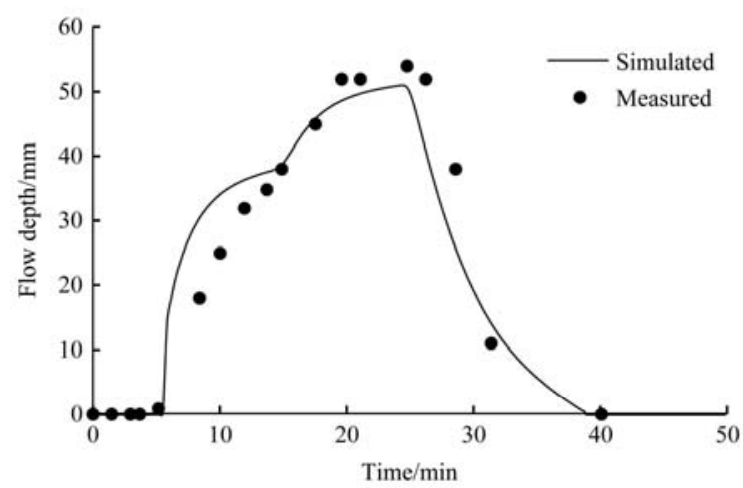

a. Border A7 depth changes with the change inflow. Therefore, the observation time interval of Field B (in 2018) was set to $30 \mathrm{~s}$. The comparisons of simulated and measured flow depths are shown in Figures 4 and 5. The simulated flow depths are closely matched with the experimental data with small relative error values. At the same time, Figure 5 also shows that the flow depth obviously changes with the variable inflow.

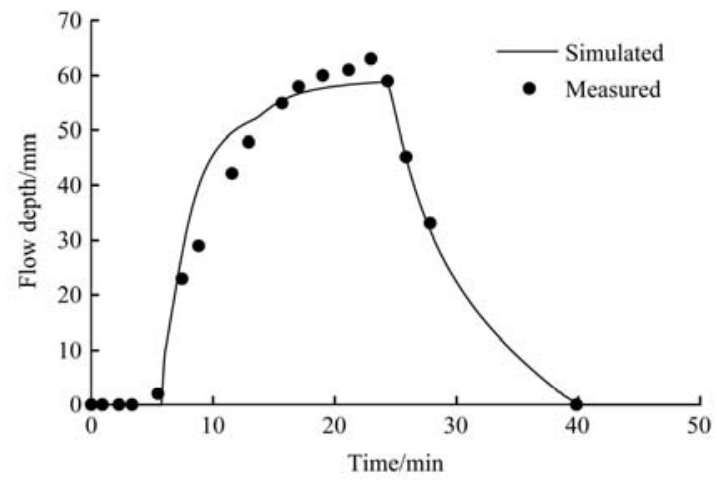

b. Border A11

Figure 4 Comparison of simulated and measured flow depths for border A7, and border A11

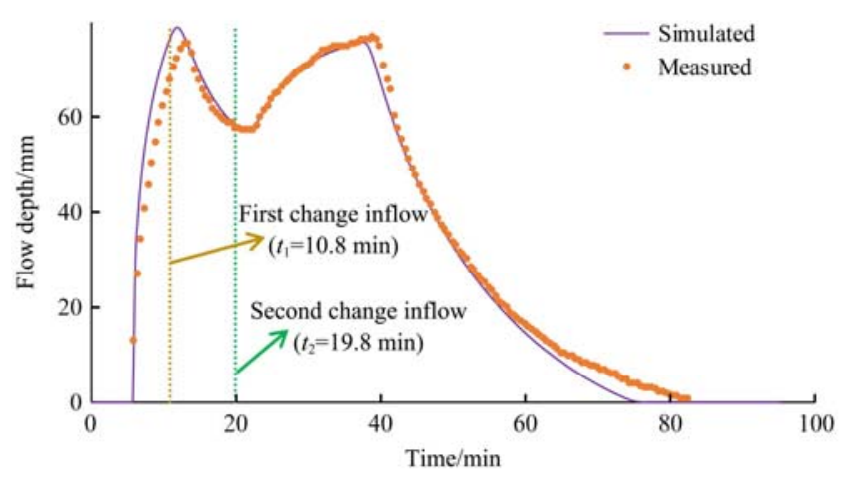

a. Border B7

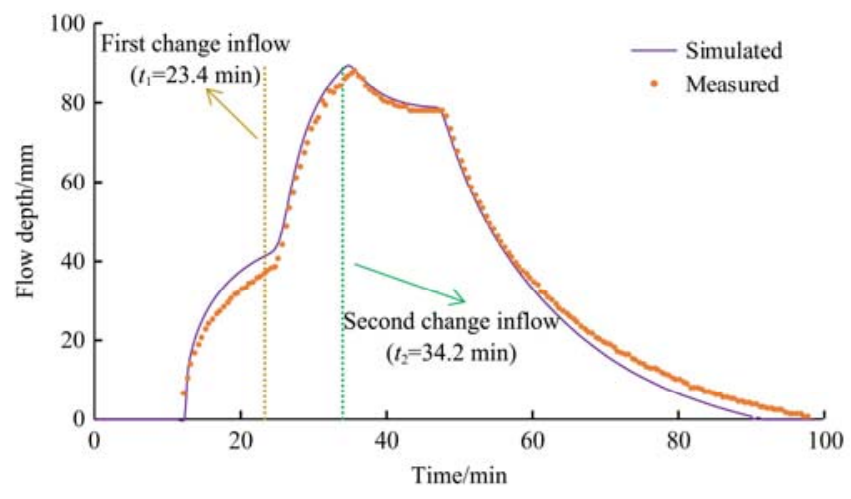

b. Border B10

Figure 5 Comparison of simulated and measured flow depths for border B7, and border B10

\subsection{Sensitivity analysis}

Because of the uncertainty of the model input parameters (bed slope, Kostiakov infiltration parameters ( $\alpha$ and $k$ ), roughness coefficient), systematic sensitivity analyses must be conducted to investigate the sensitivity of the performance to changes in these input parameters. The sensitivity analysis of $\alpha$ was only conducted because there is a certain correlation between $\alpha$ and $k^{[25]}$. Based on the input parameters of B5 (irrigation event with rapidly decreased inflow) or B8 (irrigation event with rapidly increased inflow), change only one input parameter equal $( \pm 50 \%)$ while keeping all other parameters unchanged to perform sensitivity analysis $^{[26]}$. The sensitivity index (SI) was used for this purpose, and it can indicate the percentage change in the output resulting from an input parameter changing ${ }^{[26,27]}$.

$$
\mathrm{SI}=\frac{100}{n} \sum_{i=1}^{n}\left(\frac{t_{n}-t_{p}}{t_{p}}\right)_{i} \cdot \Delta^{-1}
$$

where, $t_{p}$ is the simulated advance/recession time, $\min ; t_{\mathrm{n}}$ is the new value of simulated advance/recession time with a changed input parameter, min; $\Delta$ is the absolute value of change in the input parameter; $n$ is the number of stations along the border length.

The sensitivity of the zero-inertia model in B5 (rapidly decreased inflow) and B8 (rapidly increased inflow) is illustrated in Figure 6. In general, the infiltration parameter $(\alpha)$ was the most sensitive input variable of the zero-inertia model. In addition, the effect of model input (bed slope in particular) on the recession phase was more than the advance phase. For $-50 \%$ change in border slope, the output of advance times increased by $10.3 \%$ in B5 and $8.4 \%$ in $\mathrm{B} 8$, and that of recession times increased by $94.5 \%$ in B5 and $81.1 \%$ in B8. These results agreed with the research of Maheshwari et al. ${ }^{[27]}$ who studied the sensitivity analysis of slope for six border irrigation models in the border irrigation systems with constant inflow discharges. Their results also showed that the effect of the slope change on the recession phase is much greater than the advance phase.

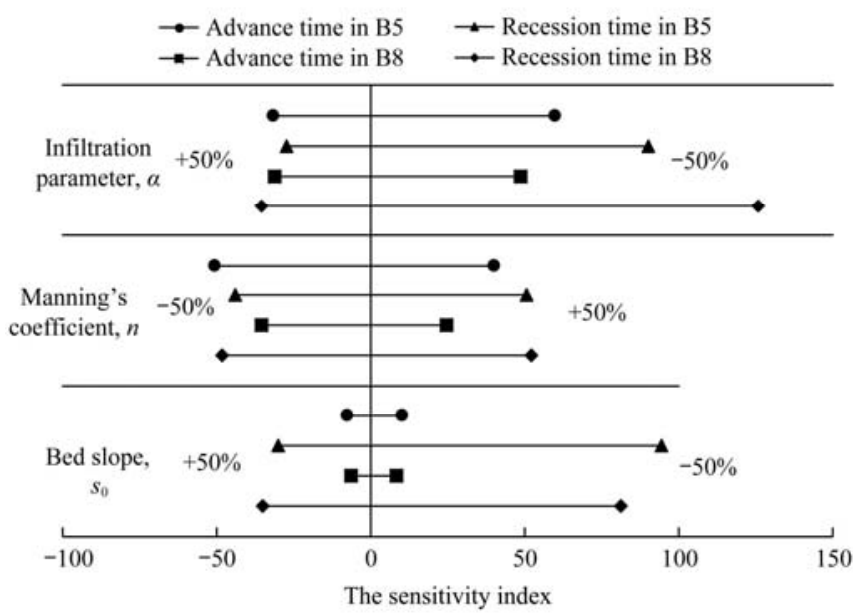

Figure 6 Sensitivity analysis of the zero-inertia model 


\section{Conclusions}

The zero-inertia model is a suitable and simple tool to simulate surface irrigation event with constant inflow discharge. Nevertheless, this model performance with rapidly varied inflow discharge was not verified. In this study, the zero-inertia model was solved using the finite difference method to verify the model with rapidly varied inflow discharge. The simulation results were compared with the experimental data. The evaluation of the model in simulating the advance and recession phases revealed that the zero-inertia model is also a good model for the surface irrigation system with rapidly varied inflow discharge. Sensitivity analysis of the input variables indicated that the infiltration parameter $(\alpha)$ was more influential than bed slope and roughness coefficient. Therefore, more attention should be paid to the measurement of infiltration parameters in rapidly varied inflow irrigation system. Moreover, for all input, especially bed slope, the recession phase was more sensitive than the advance phase.

\section{Acknowledgments}

This work was supported by the National Natural Science Foundation of China under Grant (51879073).

\section{[References]}

[1] Mcclymont D. Development of a decision support system for furrow and border irrigation. PhD dissertation. University of Southern Queensland, Toowoomba, Australia, 2007.

[2] Dholakia M, Misra R, Zaman M S. Simulation of border irrigation system using explicit maccormack finite difference method. Agric. Water Manage., 1998; 36(3): 181-200.

[3] Gillies M H, Smith R J. SISCO: Surface irrigation simulation, calibration and optimisation. Irrig. Sci., 2015; 33(5): 339-355.

[4] Barros R M, Tiago Filho G L, dos Santos I F S, Silva F G B D. Case studies for solving the Saint-Venant equations using the method of characteristics: Pipeline hydraulic transients and discharge propagation. 27th IAHR Symposium on Hydraulic Machinery and Systems; SEP 22-26; Montreal, Canada. IOP Conference Series-Earth and Environmental Science. Desy N., Deschenes C., Guibault F., Page M., Turgeon M. and Giroux A.M., ed., 2015; p. 55-62.

[5] Hauke G. A stabilized finite element method for the saint - Venant equations with application to irrigation. Int. J. Numer. Meth. Fl., 2002; 38(10): 963-984.

[6] Bradford S F, Katopodes N D. Finite volume model for nonlevel basin irrigation. J. Irrig. Drain. Eng., 2001; 127(4): 216-223.

[7] Strelkoff T, Clemmens A J. Hydraulics of surface systems. In: Hoffman G J, Evans R G, Jensen M E, Martin D L, Elliot R L, editors. Design and operation of farm irrigation systems, 2nd Ed., ASABE, St. Joseph (MO),
2007; p. 436-498.

[8] Strelkoff T, Katopodes N D. Border irrigation hydraulics with zero-inertia. J. Irrig. Drain. Div., 1977; 110(3): 325-342.

[9] Strelkoff T, Falvey H. Numerical methods used to model unsteady canal flow. J. Irrig. Drain. Eng., 1993; 119(4): 637-655.

[10] Valipour M. Comparison of surface irrigation simulation models: Full hydrodynamic, zero inertia, kinematic wave. Journal of Agricultural Science, 2012; 4(12): 68-74.

[11] Walker W R, Humpherys A S. Kinematic-wave furrow irrigation model J. Irrig. Drain. Eng., 1983; 109(4): 377-392.

[12] Valiantzas J D. Volume balance irrigation advance equation: variation of surface shape factor. J. Irrig. Drain. Eng., 1998; 123(4): 307-312.

[13] Mahdizadeh Khasraghi M, Gholami Sefidkouhi M A, Valipour M. Simulation of open- and closed-end border irrigation systems using SIRMOD. Arch. Agron. Soil Sci., 2015; 61(7): 929-941.

[14] Katopodes N D, Tang J H. Self-adaptive control of surface irrigation advance. J. Irrig. Drain. Eng., 1990; 116(5): 697-713.

[15] Han D. Concise Hydraulics. 2008. https://bookboon.com/en/ conceise-hydroulics-ebook. Accessed on [2019-05-16]

[16] Szydtowski M, Zima P. Two-dimensional vertical reynolds-averaged navier-stokes equations versus one-dimensional saint-venant model for rapidly varied open channel water flow modeling. Archives of Hydroengineering and Environmental Mechanics, 2006; 53(4): 295-309.

[17] Wang W. Spatial variability of influencing factors on border irrigation and robust design on irrigation technical parameters. $\mathrm{PhD}$ dissertation. Nanjing: Hohai University, 2009. (in Chinese).

[18] Morris M R, Hussain A, Gillies M H, O’Halloran N J. Inflow rate and border irrigation performance. Agric. Water Manage., 2015; 155: 76-86.

[19] Salahou M K, Jiao X, Lü H. Border irrigation performance with distance-based cut-off. Agric. Water Manage, 2018; 201: 27-37.

[20] Walker W R, Skogerboe G. Surface Irrigation: Theory and practice. Englewood Cliffs (NJ): Prentice-Hall Inc., 1987.

[21] Akbari M, Gheysari M, Mostafazadeh-Fard B, Shayannejad M. Surface irrigation simulation-optimization model based on meta-heuristic algorithms. Agric. Water Manage, 2018; 201: 46-57.

[22] Zhang S, Xu D, Li Y. A one-dimensional complete hydrodynamic model of border irrigation based on a hybrid numerical method. Irrig Sci., 2011; 29(2): 93-102.

[23] Cai H, Xu J, Wang J, Chen X, Zhu D, Xie F. Yearly variation of soil infiltration parameters in irrigated field based on WinSRFR4.1. Transactions of the CSAE, 2016; 32(2): 92-98. (in Chinese).

[24] Sayari S, Rahimpour M, Zounemat-Kermani M. Numerical modeling based on a finite element method for simulation of flow in furrow irrigation. Paddy and Water Environment, 2017; 15(4): 879-887.

[25] Valiantzas J D, Aggelides S, Sassalou A. Furrow infiltration estimation from time to a single advance point. Agric. Water Manage., 2001; 52(1): 17-32.

[26] Lalehzari R, Nasab S B. Improved volume balance using upstream flow depth for advance time estimation. Agric. Water Manage., 2017; 186: 120-126.

[27] Maheshwari B L, McMahon T A, Turner A K. Sensitivity analysis of parameters of border irrigation models. Agric. Water Manage, 1990; 18(4): 277-287. 